\title{
Antiwear Properties and Lubrication Mechanism of Bis(N,N-dipentylcarbamothioylthio)cadmium in Mineral Oils
}

\author{
Jian-Qiang Hu*, Yi-Qin Hu, Zhan-He Du, Yu-Hong Ma and Guang-Long Liu \\ Xuzhou Air force college \\ Xuzhou 221000, China \\ *Corresponding author: hjq5555918@163.com
}

( Manuscript received 26 December 2006; accepted 1 June 2007; published; 30 June 2007 )

\begin{abstract}
A bis(N,N-dipentylcarbamothioylthio)cadmium additive was synthesized. A four-ball tester was used to evaluate the tribological performance of the additive in mineral oil, and compared with same types of metal additives. The results show that it exhibits better anti-wear and load-carrying capacities. The surface analytical tools such as X-ray photoelectron spectrometer (XPS), Auger electron spectrometer (AES), Scanning electron microscopy (SEM) with Energy dispersive X-ray (EDX) were used to investigate the topography, the compositions contents and the depth profile of some typical elements on the rubbing surface of worn scar. Smooth topography of worn scar further confirms that the additive showed good anti-wear capacities, the results of XPS, AES and energy dispersive X-ray analyses indicated that tribochemical mixed protective films consists of cadmium atoms, sulfides and sulphates were formed on the rubbing surface, which contribute to improve the tribological properties of lubricants. Particularly, large amounts of sulfur and cadmium atoms play an important role in improving anti-wear properties of oils.
\end{abstract}

Keywords: bis(N,N-dipentylcarbamothioylthio)cadmium, additive, anti-wear, load-carrying, mechanism

\section{Introduction}

Many organic metal compounds containing phosphorus and sulphur groups were used as extreme pressure (EP) and anti-wear (AW) additives to improve the friction and wear behavior of mineral oil based lubricants. Under boundary lubrication conditions, these chemically active compounds undergo decomposition under extreme conditions (high load and high temperature) forming a protective film through the adsorption process, so the thin layer prevents welding of surface asperities and thus reduces adhesive wear ${ }^{1,2)}$. Their effectiveness is determined by their ability of form a protective film on sliding contacts. This ability is related to their action mechanism, namely physical adsorption, chemisorption or chemical reaction with the metal. Their performance depends not only on the polarity due to a functional group, but also on the quantity of chemically active elements, the activity of the decomposition products and the chemical activity of the metal surfaces ${ }^{3-5)}$.

Metal dialkyl-dithiocarbamates are mainly used as antioxidants, anti-wear, extreme pressure and anticorrosive additives for lubricating oils. They can provide particularly protection against wear similar to that achieved with additives of the prior art, but at substantially lower concentrations, or give better protection at equal concentration, metal may be selected from zinc, molybdenum, antimony, copper etc ${ }^{6,7)}$.

Thin films of soft metals are generally used to reduce wear and friction between rubbing materials when the surfaces are working under severe conditions. Cadmium coating as a solid lubricant exhibits better friction and wear properties than nickel and copper coatings tested under the same conditions thought it is banned as a harmful chemical substances by European Community regulation ${ }^{8)}$. Oil-soluble Cd (II) compounds, such as dimethyl cadmium, possess good friction reducing properties as lubricant additives ${ }^{9,10)}$. It is discovered that soft metal compounds, such as copper, tin can produce elemental metal atoms under tribochemical conditions, which deposit on the rubbing surfaces, and play a key role on lubrication and anti-wear protection ${ }^{11,12)}$.

In view of these observations, the authors have synthesizedbis(N,N-dipentylcarbamothioylthio) cadmium additive. Its anti-wear and load-carrying properties have been studied in mineral oil. The quality of the wear scar, chemical states of elements and depth profile in the reactive films have been identified by surface analysis such as XPS, AES, SEM and EDX. 


\section{Experimental}

\subsection{Oil samples and additives}

Mineral oil 500SN was used as the base oil. Bis(N,N-dipentylcarbamothioylthio)cadmium (CdDDC), was prepared by a two-step synthesis. Firstly, diamylamine was reacted with carbon disulphide in the presence of sodium hydroxide to yield corresponding sodium diamyldithiocarbamates. Further sodium salt of reactions was neutralized with cadmium chloride to produce CdDDC in distilled water. The additive antimony diamyl-dithiocarbamate (SbDDC) and molybdenum dialyl-dithiocarbamate (MoDDC) was commercially purchased from R.T. Vanderbilt company, and the dibutyl tin dibutyl-dithiocarbamate (SnDDC) and bismuth diamyl-dithiocarbamate (BiDDC) were synthesized in the lab.

\subsection{Tribological tests}

Tribological performances of mineral oil containing additives were evaluated with a four-ball machine at a rotating speed $1450 \mathrm{rpm}$, test duration of $30 \mathrm{~min}$, room temperature about $25^{\circ} \mathrm{C}$. The balls used in the tests were made of GCr15bearing steel (AISI52100) at a diameter of $12.7 \mathrm{~mm}$ with HRC of 59 to 61 . The average of the three wear scar diameters was calculated and cited as the wear scar diameter reported in this paper.

\subsection{Surface analysis}

Profiles and elemental distributions of the worn surfaces were obtained using scanning electron microscopy (SEM). The chemical states of surface films were investigated using PHI 5300 X-ray photoelectron spectrometer (XPS). XPS analysis was investigated the chemical states of the elements present, the radiation source was $\mathrm{Mg} \mathrm{K} \alpha$ line with pass energy of $29.35 \mathrm{eV}$ and $\mathrm{Ar}+$ ions of $3000 \mathrm{eV}$ energy were used for sputtering. All binding energies were compared with a reference standard of $284.6 \mathrm{eV}$ for carbon. The depth profile of elements present was investigated using $\mathrm{PHI}$ 610 Auger electron spectrometer (AES). This was done with an electron beam energy of $3 \mathrm{KV}$. The depth profile was accomplished by sputtering through the surface layer using a $25 \mathrm{~mA}$ and $1 \times 1 \mathrm{~mm}^{2}$. Argon ion beam at an estimated rate of $30 \mathrm{~nm} / \mathrm{min}$. Before analysis, all samples were ultrasonically rinsed with hexane and petroleum ether for $10 \mathrm{~min}$.

\section{Results and discussion}

3.1. Evaluation on tribological performance in mineral oil

Bis(N,N-dipentylcarbamothioylthio)cadmium (CdDDC) was added to the 500SN oil and the resultant anti-wear properties were evaluated by the four-ball friction tester under loads of 392 and $588 \mathrm{~N}$ load for 30 min according to ASTM D4172-82. The load-carrying capacities of additive were characterized as maximum non-seizure load $\left(\mathrm{P}_{\mathrm{B}}\right.$ value) and weld load $\left(\mathrm{P}_{\mathrm{D}}\right.$ value $)$ which was evaluated according to ASTM D2783-88. The relationships between its performances and the concentrations are also given, for comparison, the performances of SbDDC, BiDDC, SnDDC and MoDDC were also evaluated.

The wear scar diameter (WSD) of tested balls and the $P_{B}$ and $P_{D}$ values of oil containing different additives are organized in Table 1, from which we can see clearly that the WSD adding CdDDC was smaller than base oil, and obviously smaller than SbDDC, BiDDC, SnDDC and MoDDC respectively under same conditions. Moreover, the anti-wear capacity increases are not obvious when the concentration of $\mathrm{CdDDC}$ is greater than $1.0 \%$. In addition, the results summarized indicate that CdDDC could improve load-carrying properties of the base oil obviously, the $\mathrm{P}_{\mathrm{B}}$ and $\mathrm{P}_{\mathrm{D}}$ values of the base oil are enhanced by $75 \%$ and $56 \%$ respectively at $1.5 \%$. The PB and of $\mathrm{P}_{\mathrm{D}}$ values oil containing CdDDC are better than SbDDC, SnDDC and MoDDC, only $\mathrm{P}_{\mathrm{D}}$ value is lower than BiDDC which is an excellent extreme pressure additive. As a whole, CdDDC additive possesses better anti-wear and load carrying properties among the same types of metal additives.

\subsection{Surface analysis}

\subsubsection{X-ray photoelectron spectroscopy (XPS)}

The four-ball worn surfaces, produced by being rubbed in the oil containing 2.0\% CdDDC for $30 \mathrm{~min}$ at a load of $588 \mathrm{~N}$, were analyzed by XPS. The $\mathrm{Cd}_{3 \mathrm{~d}}$ and $\mathrm{S}_{2 \mathrm{p}}$ XPS spectra are shown in Fig. 1 (a) (b). It can be seen

Table 1 Wear scar diameter and load-carrying capacities with oils containing CdDDC

\begin{tabular}{|c|c|c|c|c|c|}
\hline \multirow{2}{*}{ Additive } & \multirow{2}{*}{$\begin{array}{c}\text { Concentration } \\
\text { wt. } \%\end{array}$} & \multicolumn{2}{|c|}{ Wear scar diameter, $\mathrm{mm}$} & \multirow{2}{*}{$\begin{array}{c}\text { Maximum non } \\
\text { seizure load } \mathrm{P}_{\mathrm{B}}, \mathrm{N}\end{array}$} & \multirow{2}{*}{$\begin{array}{l}\text { Weld load } \\
\mathrm{P}_{\mathrm{D}}, \mathrm{N}\end{array}$} \\
\hline & & $392 \mathrm{~N}$ & $588 \mathrm{~N}$ & & \\
\hline $500 \mathrm{SN}$ & 0 & 0.632 & 0.873 & 549 & 1568 \\
\hline \multirow{4}{*}{ CdDDC } & 0.5 & 0.590 & 0.802 & 882 & 1960 \\
\hline & 1.0 & 0.531 & 0.770 & 882 & 1960 \\
\hline & 1.5 & 0.492 & 0.795 & 980 & 2450 \\
\hline & 2.0 & 0.528 & 0.753 & 980 & 2450 \\
\hline SbDDC & 2.0 & 0.633 & 0.835 & 804 & 1960 \\
\hline BiDDC & 2.0 & 0.638 & 0.955 & 882 & 3920 \\
\hline SnDDC & 2.0 & 0.582 & 0.913 & 745 & 1960 \\
\hline MoDDC & 2.0 & 0.612 & 0.887 & 598 & 1960 \\
\hline
\end{tabular}




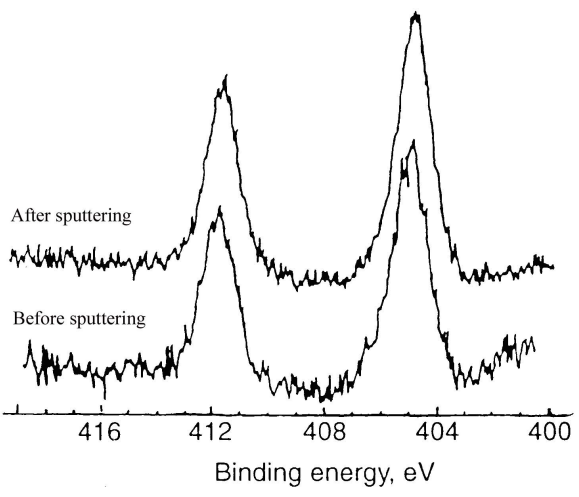

(a) $\mathrm{Cd}_{3 \mathrm{~d}}$ XPS spectra

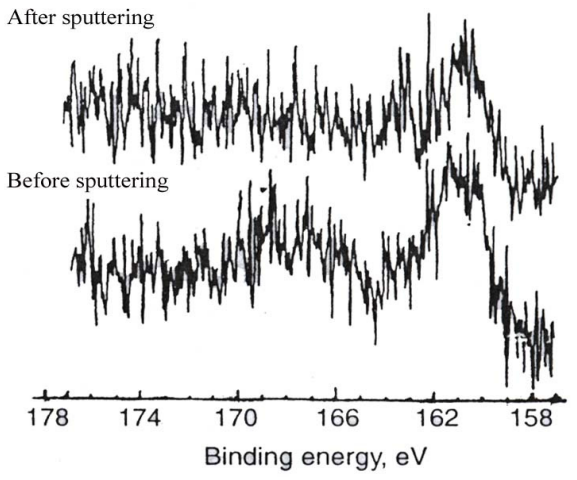

(b) $S_{2 p}$ XPS spectra

Fig. 1 XPS spectra of elements $\mathrm{Cd}$ and $\mathrm{S}$ on the worn scar before and after sputtering for $5 \mathrm{~min}$

from Fig. 1(a) that, before and after sputtering, cadmium atoms could be detected on the worn surface, the binding energy of $\mathrm{Cd} 3 \mathrm{~d}$ at $405.4 \mathrm{eV}$ and the difference between $\mathrm{Cd} 3 \mathrm{~d} 3 / 2$ and $\mathrm{Cd} 3 \mathrm{~d} 5 / 2$ is 6.7 , are consistent with the standard electron binding energy of a simple cadmium atom $^{13)}$. Thus, we can also confirm existence of cadmium (0) atom formed on the surface.

In Fig. 1(b), the binding energy of S $2 \mathrm{p}$ are $161.2 \mathrm{eV}$ and $168.8 \mathrm{eV}$ which correspond to $\mathrm{FeS}, \mathrm{FeSO}_{4}$ before sputtering, indicates that tribochemical reactions occur between the additives and metal surfaces during the sliding process. The anti-wear additive containing sulphur can be adsorbed on metal surfaces, and react with the metal to form protective films that help to reduce metal contact. However, after $10 \mathrm{~min}$ of sputtering, the peak $\left(\mathrm{FeSO}_{4}\right)$ at binding energy of $168.8 \mathrm{eV}$ is disappear, only $\mathrm{FeS}$ exists on inner surface. It is concluded that FeS layer is effective on reducing the wear and increasing the load-carrying capacity.

\subsubsection{Auger electron spectroscopy (AES)}

Fig. 2 gives the AES spectra profiles of a wear scar lubricated with CdDDC under load of 588 N. Auger depth profile technique can provide the distribution of the relative atomic concentration of elements in the films. From which we can observe that there are a large number of cadmium atoms on the top layer of two rubbed surfaces, and with the increase of sputter time, the contents of cadmium atoms decreased. After sputtering for $0.5 \mathrm{~min}$, cadmium atoms disappeared, at the same time, the atomic concentrations of sulfur attain the maximum, then it decreased gradually with the increase of sputter time.

3.2.3 Scanning electron microscopy (SEM) with Energy dispersive X-ray (EDX)

Fig. 3 (a), (b), (c), (d) show the worn scar micrographs of the steel balls lubricated by $500 \mathrm{SN}$ oil and the with $0.5 \%$ CdDDC addtive under 392 and 588 N. From which we can see clearly that the wear area with base oil was slightly larger than oil containing CdDDC under same loads. Especially, under load of $588 \mathrm{~N}$, the enlarged micrographs $(\times 500)$ display the one lubricated by basic oil had already been broken, but the scratched surface lubricated by CdDDC is better than base oil, therefore, above evidences further prove that CdDDC exhibits better anti-wear properties as a lubricant additive.

In addition, the EDX spectra of worn scar are shown in Fig. 4 and 5, the atomic concentrations of the elements evaluated on the worn scars by SEM-EDX are listed in Table 2. The results of EDX show that more cadmium and sulfur atoms were formed on the worn scar at $588 \mathrm{~N}$ than at $392 \mathrm{~N}$. It is suggested that decomposition of the additive was accelerated by increasing loads so that more sulfur and cadmium atoms were produced. On the rubbing surfaces, the sulfides formed from active sulfur could reduce wear and increase the load-carrying capacities, also cause corrosive wear deteriorating rubbing surface qualities. However, the soft cadmium layer promoted by tribo-reduction not only reduces friction and wear due to its low melting point $321^{\circ} \mathrm{C}$, but also inhibits corrosion, they provides positive effects on lubrication largely by improving the anti-wear and load-carrying capacity.

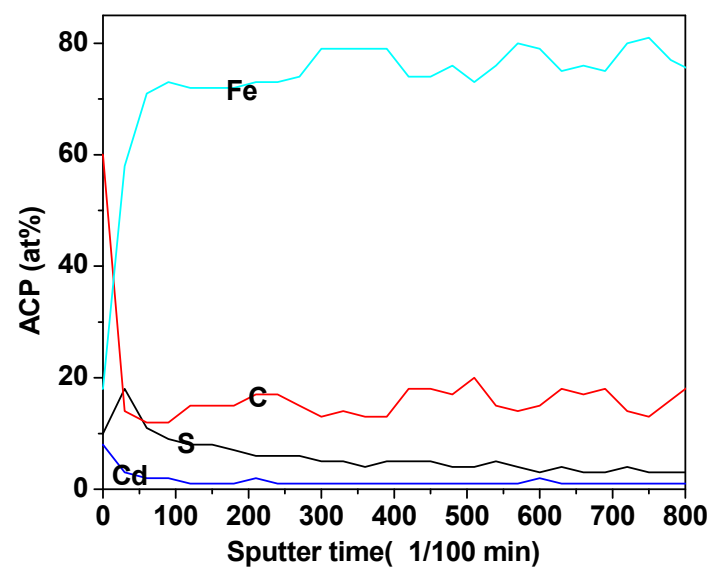

Fig. 2 AES depth profile of CdDDC at $588 \mathrm{~N}$ 

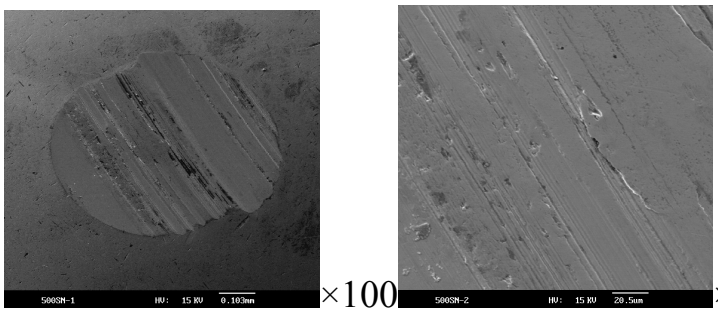

$\times 500$

(a) Base oil at $392 \mathrm{~N}$

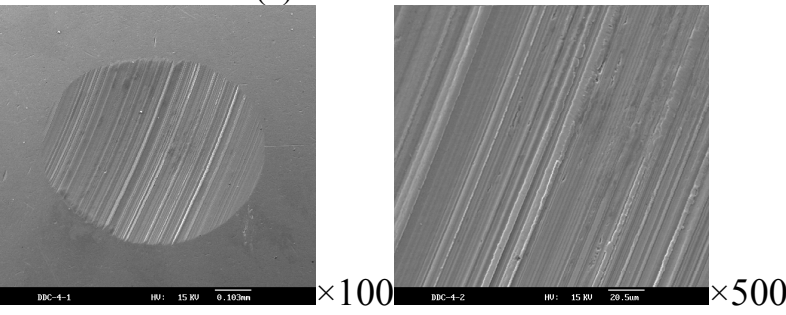

(b) $\mathrm{CdDDC}$ at $392 \mathrm{~N}$

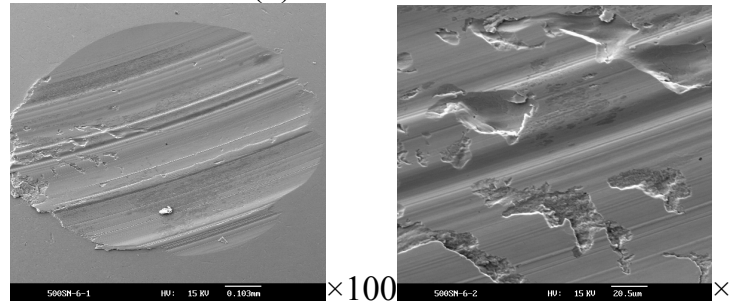

$\times 500$

(c) Base oil at $588 \mathrm{~N}$

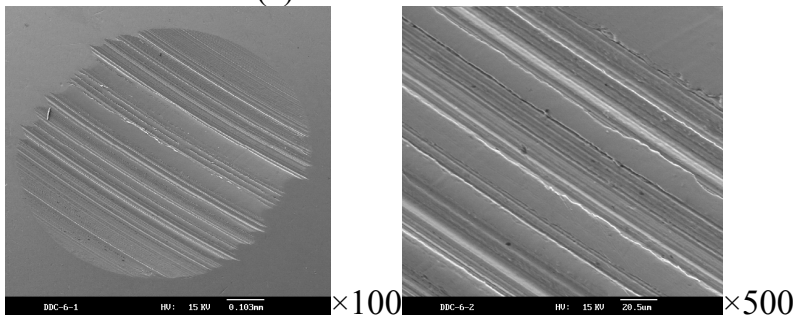

(d) CdDDC at $588 \mathrm{~N}$

Fig. 3 SEM morphologies of worn scar lubricated with the 500SN, CdDDC under different load

\section{Conclusion}

(1) Bis(N,N-dipentylcarbamothioylthio)cadmium synthesized possesses better anti-wear and load carrying capacities than other metal additives containing same structure in lubricants, such as SbDDC, SnDDC and MoDDC.

(2) The surface examination of the rubbing zone indicated that there is a protective layer consisting of cadmium compounds, sulfides, sulphates in the sliding process. Especially the existence of FeS and cadmium atoms produced by tribo-reduction helps to improve the tribological performances of oils.

\section{References}

[1] Kubo, K., Shimakawa, Y. and Kibukawa, M., "Study on the Load Carrying Mechanism of Ulphur-phosphorus Type Lubricants," in Proceedings of the JSLE International Tribology Conference, Tokyo, Japan, 3, 1985, 661-666.

[2] Unnikrishnan, R., Jain, M. C., Harinarayan, A. K. and Mehta, A. K., "Additive-additive Interaction: an XPS Study of the Effect of ZDDP on the AW/EP Characteristics of Molybdenum Based Additives," Wear, 252, 2002, 240-249.

[3] Matveevsky, R. M., "Chemical Modification of Friction Surfaces in Boundary Lubrication," ASLE Trans., 24, 1981, 483-488.

[4] Willermet, P. A., Carter, R. O. and Boulos, E. N., "Lubricant-derived Tribochemical Films -An Infra-red Spectroscopic Study," Tribology International, 25, 1992, 371-380.

[5] Uetz, H., Khosrawi, M. A., Fohl, J., "Mechanism of Reaction Layer Formation in Boundary Lubrication," Wear, 100, 1984, 301-311.

[6] Tuli, D. K., Sarin, A. K., Kumar, A. K, et al., "Synthetic Metallic Dialkyldithiocarbamates as Antiwear and Extreme-pressure Additives for Lubricating Oils: Role of Metal on Their Effectiveness," Lubrication Engineering, 51, 1995, 298-303.

[7] Wolfram, S. and Rolf, H., "Process for the Preparation of Dialkyldithiocarbamates of Multivalent Metals," USP 4859787, 1989.

[8] Ruggeri, O., Sambogna, G. and Balboni, C. P., "Dry Lubrication with Soft Metals: The Tribological Behaviour of a Thin Film of Cadmium Rubbing on Carbon Steel," Wear, 59, 1980, 433-446.

[9] Dorinson, A. and Cludma, K., "Mechanics and Chemistry in Lubrication," Elsevier Science Publishers, Amsterdam, 1985, 533-536.

[10] Rowe, C. N. and Dickert, J. J., "The Relation of Antiwear Function to Thermal Stability and Structure for Metal: O,O-Dialkylphosphorodithioates," ASLE Trans., 10, 1967, 85-90.

[11] Yao, J. and Dong, J., "Anti-wear Synergism of Borates and Copper Oleate," Lubrication Engineering, 50, 1994, 657-663.

[12] Ozimina, D. and Kajdas, C., "Tribological Properties and Action Mechanism of Complex Compounds of Sn (II) and Sn (IV) in Lubrication of Steel," ASLE Trans., 30, 1986, 508-519.

[13] Wagner, C. D., Riggs, W. M., Davis, L. E., Moulder, J. F. and Muilenberg, G. E., "Hand book of X-Ray Photo Electron Spectroscopy," Perkin-Elmer Corporation, Physical Electronics Division, Minnesota, 1979, 437. 